\title{
DOI 10.17150/2308-6203.2019.8(4).735-746
}
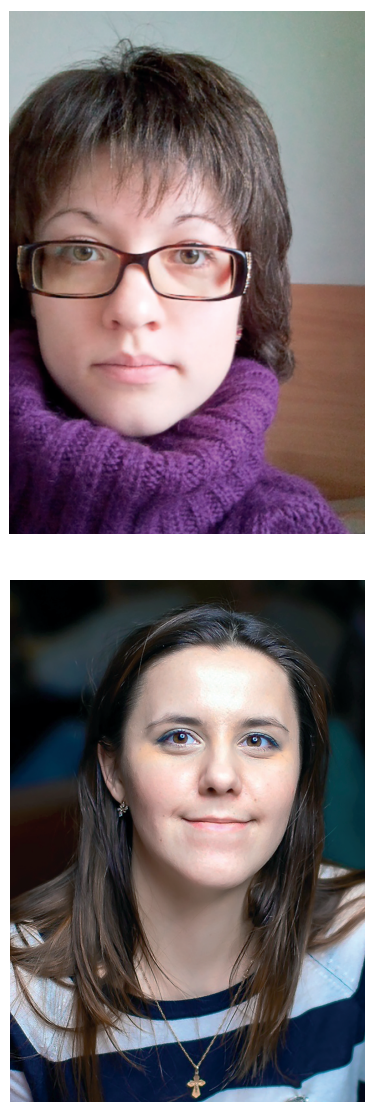

\section{Авдонина Наталья Сергеевна}

Кандидат политических наук, доцент

Кафедра журналистики, рекламы и связей с

общественностью, Северный (Арктический) федеральный университет имени М.В. Ломоносова, 163002, Российская Федерация, г. Архангельск, наб. Северной Двины, д. 17, e-mail: natalia.avdonina1987@gmail.com

\section{Natalia S. Avdonina}

$\mathrm{PhD}$ in Political Sciences, Associate Professor

Department of Journalism, Advertising and PR, Northern (Arctic) Federal University named after M.V. Lomonosov, 17 Severnaya Dvina Emb., Arkhangelsk, 163002,

Russian Federation, e-mail: natalia.avdonina1987@gmail.com

\section{Долгобородова Светлана Олеговна \\ Аспирант}

Высшая школа журналистики и массовых коммуникаций, Санкт-Петербургский государственный университет, 199034, Российская Федерация, г. Санкт-Петербург, Университетская наб., д. 7-9, e-mail: dol21031967@yandex.ru

\section{Svetlana O. Dolgoborodova}

PhD Student

School of Journalism and Mass Communications, St.-Petersburg State University, 7-9, Universitetskaya Emb., St Petersburg, 199034, Russian Federation, e-mail: dol21031967@yandex.ru

\section{ПРОБЛЕМА ОСВОЕНИЯ АРКТИКИ В ГОСУДАРСТВЕННОМ МЕДИАДИСКУРСЕ РОССИИ: НА ПРИМЕРЕ «РОССИЙСКОЙ ГАЗЕТЫ", ОФИЦИАЛЬНОГО ИЗДАНИЯ ПРАВИТЕЛЬСТВА РФ}

Аннотация. Тенденции официального арктического медиадискурса России - это устойчивый интерес к темам национального развития в Арктике, геополитической обстановке в регионе и наращиванию военного потенциала России на севере. Данная статья посвящена анализу тенденций в освещении арктической проблематики в официальном российском арктическом дискурсе на примере официального печатного органа правительства РФ «Российская газета».

Хронологические рамки исследования представлены периодом 2001-2018 гг., поскольку в это время актуализируется арктический дискурс. Динамика арктического медиадискурса России подразделяется на два периода: 2001-2007 гг. и 2008-2018 гг. Ключевым моментом для проведения границы между этапами послужила российская экспедиция 
«Арктика-2007», в рамках которой на дне Северного Ледовитого океана был установлен фрлаг России. Для первого этапа характерны невысокая частота публикаций и нейтральная эмоциональная окраска текстов. На втором этапе дискурса наблюдаются тематическое расширение журналистских текстов об Арктике, реакционность и агональность дискурса.

В результате проведенного анализа был сделан вывод, что, обращаясь к арктической проблематике, издание придерживается официальной позиции российской власти. В связи с этим мы отметили явочный характер публикаций.

Ключевые слова. Арктика, медиадискурс, российский арктический медиадискурс, информационная политика, динамика публикаций.

Информация о статье. Дата поступления 23 ноября 2018 г.; дата принятия к печати 2 октября 2019 г;; дата онлайн-размещения 26 октября 2019 г.

\section{COVERAGE OF THE ARCTIC DEVELOPMENT IN RUSSIAN MASS MEDIA DISCOURSE (BY THE EXAMPLE OF "ROSSIYSKAYA GAZETA")}

\footnotetext{
Abstract. The trends in the official Russian arctic media discourse reflect a sustainable public interest to the issues of the Arctic national development, as well as to the geo-political situation and Russia's military buildup in the North. The article analyzes the trends in the coverage of Arctic-related issues in the official Russian discourse by the example of "Rossiyskaya Gazeta" the official print newspaper of RF government.

The study covers the period of 2001-2018, which is characterized by topicality of arctic discourse. The dynamics of the discourse can be visibly divided into two stages. The first stage started in 2001 and finished in 2007 with the Russian expedition "Arctic-2007", which planted the flag of the Russian Federation on the bottom of the Arctic Ocean. The discourse of the stage features low frequency of publications on the topic and neutral emotional text sentiment. The discourse of the second stage (2008-2018) exhibits a noticeably wider topical range of publications on Arctic-related issues, as well as their reactionary and agonic spirit.

The analysis resulted in an inference that the publications on Arctic-related problems in the newspaper reflect the official position of RF authorities, and have a specific-reason character.

Keywords. The Arctic, media discourse, Russian arctic media discourse, information policy, dynamics of publications.

Article info. Received November 23, 2018; accepted October 2, 2019; available online October 26, 2019.
}

\section{Введение}

Интерес к Арктике в наши дни настолько велик, что на Западе XXI столетие окрестили «веком Арктики». Возрастающее внимание к этому региону объясняется рядом причин. Прежде всего, как отмечают исследователи, Арктика - резерв свободного пространства. Сопоставить этот регион можно лишь с Антарктикой, однако географическое расположение Арктики гораздо выгоднее: она относительно ближе к развитым странам Европы и Северной Америки. А технический прогресс только приближает аркти- 
ческий регион к «промышленным» центрам, постепенно включая его в общие процессы интеграции и глобализации [1, с. 23].

Другая важная причина интереса к Арктике - ее неоспоримые природные богатства: месторождения нефти и газа, как на шельфе, так и на суше [2].

Можно отметить целый ряд работ, посвященных вопросу Арктического региона в геополитическом пространстве [3-9]. Отдельный спектр исследований занимает медиадискурс Арктического региона [10;11].

В 1982 г., когда состоялась третья конференция ООН по морскому праву, была принята Конвенция Организации Объединенных Наций по морскому праву. ${ }^{1}$ Это важнейший документ, который служит основой для регулирования процесса разделения не только арктических, но и любых морских территорий и по сей день. На эту же Конвенцию, следовательно, ссылаются и СМИ, поднимая проблему освоения арктических территорий. В контексте арктической проблематики Конвенция 1982 г. невероятно важна. Она дала определение таким понятиям как внутренние воды, исключительная экономическая зона, континентальный шельф и пр., т.е. декларировала самые спорные вопросы раздела Арктики. Аналитик П.А. Гудев пишет, что «одним из главных последствий подписания Конвенции стала смена существовавшей ранее дуалистической системы разделения пространств Мирового океана на многостороннюю или же мультилатералистскую»

\footnotetext{
${ }^{1}$ Конвенция Организации Объединенных Наций по морскому праву // Собрание законодательства РФ. 1997. № 48. Ст. 5493.
}

[12, с. 67]. Ключевая идея заключается в том, что Конвенция ограничила суверенитет государств: «составной частью Конвенции стала единая система урегулирования споров; «суверенные права» были поставлены в прямое подчинение задачам сохранения, защиты окружающей среды; обосновывалась необходимость международного / двухстороннего сотрудничества в вопросах защиты окружающей среды, управления живыми / неживыми ресурсами» [2, р. 59]. С тех пор национальные интересы каждой циркумполярной страны могут реализовываться на легитимной основе международного права. Любое циркумполярное государство может претендовать лишь на двухсотмильную экономическую зону моря, отсчет которой идет от точки берега. Остальная территория - международные воды.

Тема Арктики активно освещается российскими журналистами. Согласно данным мониторингового агентства Integrum, в 2001-2018 гг. в более чем 100000 тысячах текстов российских СМИ упоминается Арктика. В 2001 г. этот показатель был в четыре раза ниже, а наиболее резкий рост числа публикаций пришелся на 2007 и 2015 г., что отражено на рис. 1.

По мнению Е.И. Булатовой, в 2007 г. в зарубежных СМИ развернулась информационная война за ресурсы Арктики, что позволяет говорить о появлении арктического медиадискурса как «тематически сорокусированной на вопросах освоения Арктики речемыслительной деятельности в массмедийном пространстве» [13, с. 90]. Исследователь дает следующее определение арктическому медиадискурсу — это 
Theoretical and Practical Issues of Journalism, 2019, vol. 8, no. 4, pp. 735-746

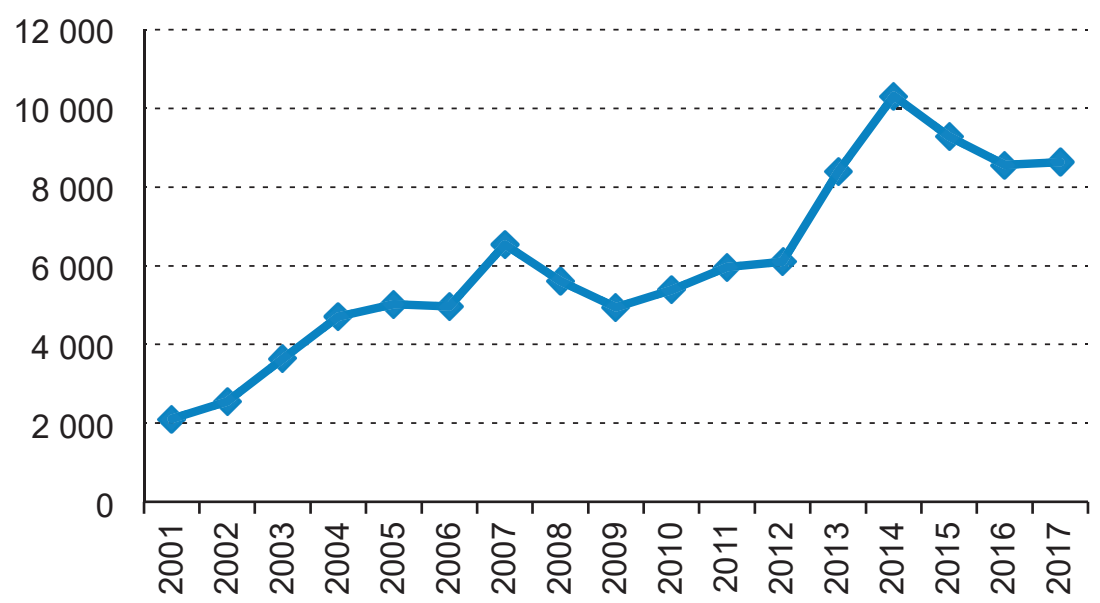

Рис. 1. Арктический медиадискурс за период 2001-2017 гг.

«тематически сорокусированная на вопросах освоения Арктики речемыслительная деятельность в массмедийном пространстве» [13, с. 88].

Постепенно медиадискурс приобретает агональность (состязательность). Это вызвано не только установкой российского флага в Арктике, но и тем, пишет Е.И. Булатова, что одна из центральных тем, широко освещаемых как в российских, так и в зарубежных СМИ, - борьба за арктический шельф. С.И. Виноградов объясняет, что «персуазивность (агональность) выражается в намеренном воздействии на когнитивно-ментальную сферу читателя с целью добиться нужного манипулятору результата» [14, с. 89].

Динамика арктического медиадискурса России (рис. 1) демонстрирует, что в 2007 г. происходит перелом: количество журналистских материалов увеличилось в три раза, по сравнению с данными 2001 г. Таким образом, формирование отечественного арктического медиадискурса можно подразделить на два периода: 20012007 гг. и 2008-2018 гг.

\section{Информационная политика РФ в отношении Арктического региона: обзор}

Г.В. Чевозерова трактует информационную политику как производство целенаправленных изменений объектов, процессов, явлений с помощью передаваемой информации [15, c. 206].

Так как Россия предстает и в информационной политике и в стратегических документах циркумполярных стран как особый партнер, остановимся подробнее на арктической стратегии РФ, которая берется за основу и для информационной политики отечественных СМИ. Для этого важно понять национальные интересы России в Арктическом регионе. Прежде всего, это экономические интересы. Уже в 2011 г. арктический регион обеспечивал около 11 \% национального дохода России в связи с добычей значительного количества углеводородов и других полезных ископаемых, важных в промышленном потенциале страны. ${ }^{2}$ Арктический

${ }^{2}$ Арктические перспективы России. URL: http://ru.apircenter.org/archives/3089. 
регион важен и для обеспечения безопасности РФ: здесь сосредоточен ряд важнейших предприятий оборонной промышленности. Государственная граница РФ проходит по Северному Ледовитому океану на протяжении 20 тыс. км. На Кольском полуострове базируется Северный флот России.

Исследователи отмечают, что Россия стремится занимать взвешенную позицию, ориентированную на сотрудничество с другими государствами, не упуская из вида военную активность в регионе других государств [16, с. 46]. Это подтверждается позицией членов МИД. Представитель российского МИД А. Васильев однажды заявил, что «многие из оценок средств массовой информации о возможном противостоянии в Арктике, вплоть до третьей мировой войны, представляются чрезмерно алармистскими и провокационными». ${ }^{3}$ Это важное замечание в контексте отражение государственной политики РФ в Арктике в отечественной информационной политике.

Основные усилия российского руководства направлены на расширение границ континентального шельфа России за пределы 200-мильной зоны в сторону полюса. Чтобы доказать свои права на шельф, Россия неоднократно проводила арктические экспедиции: «Арктика-2000», «Арктика-2005», «Арктика-2007», «Арктика» (2008-2013 гг.).

В сентябре 2008 г. президентом Д.А. Медведевым утверждается новый стратегически важный документ «Основы государственной политики

${ }^{3}$ МИД РФ назвал заявления о противостоянии в Арктике провокацией. URL: http:// vz.ru/news/2008/10/22/221696.html.
Российской Федерации в Арктике на период до 2020 г. и дальнейшую перспективу». Согласно этому документу, главными национального интересами России в Арктике являются:

- использование Арктической зоны России в качестве стратегической ресурсной базы, обеспечивающей решение задач социально-экономического развития страны;

- сохранение Арктики в качестве зоны мира и сотрудничества;

- сбережение уникальных экологических систем Арктики;

- использование Северного морского пути в качестве национальной единой транспортной коммуникации РФ в Арктике.

Согласно планам комплексного развития северных территорий к 2016-2020 гг. Арктика должна стать не просто ресурсной, а «ведущей стратегической ресурсной базой» России.

В сфере обеспечения безопасности стратегической целью названы «обеспечение благоприятного оперативного режима в арктической зоне РФ, включая содержание необходимого боевого потенциала группировок войск (сил) общего назначения Вооруженных сил РФ, других войск, воинских формирований и органов в этом регионе». ${ }^{4}$ Под этим имеется ввиду усиление Службы береговой охраны ФСБ и пограничного контроля в Арктической зоне Российской Федерации и организация технического контроля за проливами, устьями рек, лиманами на всей трассе Северного морского пути.

${ }^{4}$ Основы государственной политики Российской Федерации в Арктике на период до 2020 г. и дальнейшую перспективу. URL: https://rg.ru/2009/03/30/arktika-osnovy-dok.html. 
Исследователи объясняют, что такой формулировкой перед арктической группировкой вооруженных сил ставится не только задача защиты территории, но и защиты экономических интересов России во всем арктическом пространстве [16, с. 50].

Несмотря на активность арктической политики РФ, исследователи признают, что ей не хватает цельности и «решительности». Констатируют низкий уровень исполнительной дисциплины чиновников, и, как следствие, невыполнение или частичное выполнение значительной части законодательных решений. Арктическую политику характеризуют как не имеющую общей стратегии осуществления на долгую перспективу. Основное отличие российского подхода к освоению Арктики связано с рассмотрением ее, в первую очередь, как ресурсного потенциала для развития страны, а для остальных стран, имеющих интересы в Арктике, как условие экономической безопасности [17, с. 98].

Исследователь арктического медиадискурса Э.В. Ров отмечает, что информационная политика приарктических государств складывается на базе арктических стратегий государств, поэтому для разных приарктических государств характерны интерпретации в СМИ разных сторон проблемы освоения Арктики [18].

Ю.Ф. Лукин констатирует, что в начале современного столетия в Арктике «практически сорормировалось конфликтное геополитическое пространство, которое стало такой же реальностью, как Полярная звезда на небе или фолаг России на дне Северного Ледовитого океана» [19, с. 117]. Конфликты имеются или имелись в начале XXI столетия практически у всех приполярных государств (Канады и США, России и Норвегии, Дании и Канады и пр.), что затронуло и медиасреду.

\section{Информационная политика «Российской газеты» относительно темы освоения Арктики в 2001-2007 гг.}

В начале тысячелетия одним из ключевых арктических событий в России являлась подача первой заявки России в Комиссию $\mathrm{OOH} \mathrm{с} \mathrm{це-}$ лью расширения территорий арктического шельфа. На тот момент расширение России в арктическом регионе не является актуальной темой ни для читателей, ни для, вероятно, Правительства, поскольку официальное издание не посвящает теме отдельных материалов. Издание впервые упоминает заявку в 2002 г., но только в контексте деятельности Министерства природных ресурсов России, где Арктика в целом предстает как «болевая точка» деятельности Министерства. ${ }^{5}$

В целом арктические вопросы, освещаемые журналистами «Российской газеты» в 2001 г., можно представить в формате диаграммы:

В 2005 г. в «Российской газете» тематическое соотношение публикаций об Арктике остается примерно таким же. Эмоциональная окраска текстов на данном этапе может быть охарактеризована как нейтральная и даже мягкая. Например, заголовки текстов отражают стремление России к увеличению площади за счет севера, но мирным путем: «Хребет Ломоносова. Россия может прирастить свои владения без войны и аннексий».

${ }^{5}$ Министерский этюд в природных тонах // Российская газета. 2002. 5 июня. 


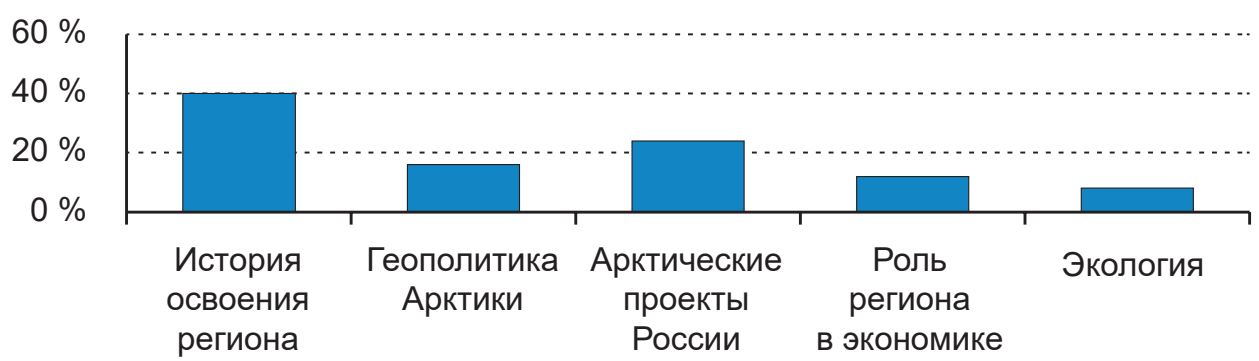

Рис. 2. Тематическое соотношение текстов об Арктике в Российской газете в 2001 г.

В 2007 г. арктический дискурс в издании меняется, как качественно, так и количественно. Причиной является экспедиции «Арктика-2007», во время которой на дне Северного Ледовитого океана был установлен российский фрлаг. Об экспедиции сообщили все авторитетные средства массовой информации. Редакция газеты «Московский комсомолец» отправила своего корреспондента «вместе с полярниками покорять вековые льды» [20], тем самым, подготовив серию публикаций.

В «Российской газете» за 2007 г. опубликовано 24 материала, так или иначе связанных с экспедицией «Арктика-2007», и 71 материал на аркти- ческую тематику в целом. В 2001 г. в издании было опубликовано всего 25 материалов об Арктике, в 2005 г. 21 текст, а в 2006 г. - 20. Таким образом можно сделать вывод, что до 2007 г. динамика публикаций существенно не менялась, а в 2007 г. частота публикаций на тему Арктики в «Российской газете» выросла в три раза, что показано на рисунке 3 .

В 2007 г. отечественный арктический дискурс приобретает уже и более явный милитаристический характер: ключевая идея - готовность России к возможной борьбе за Арктику. Заголовки, являющиеся сами по себе сосредоточением идеи текста, в 2007 г. принципиально меняются:

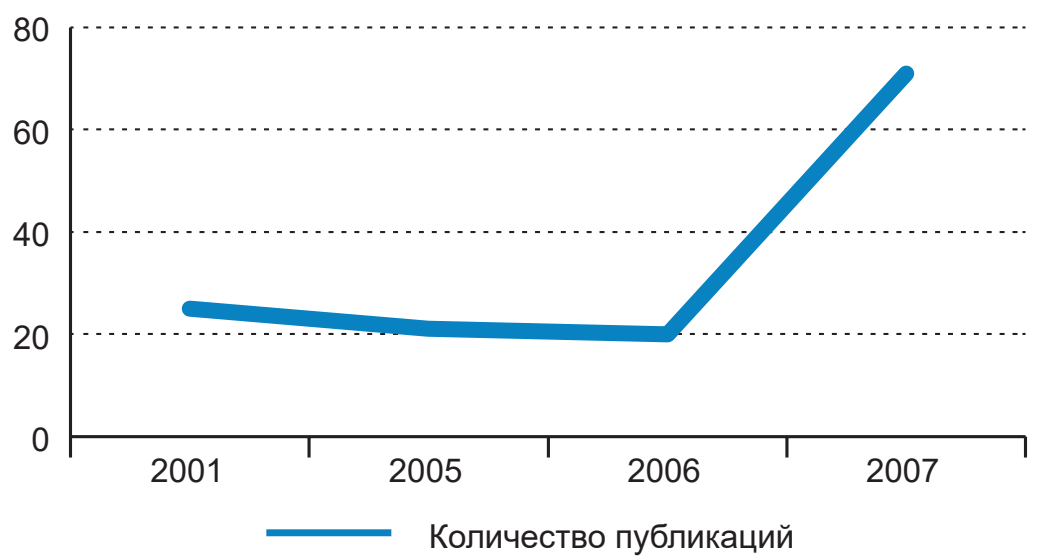

Рис. 3. Динамика развития арктической темы в «Российской газете» в 2001-2007 гг. 
«Вернуть позиции морской державы», «Битва за Арктику», “Схватка за Арктику», "Схватка за полюс», «Шельфр взят!...», «Еще один бросок в Арктику» и т.п. Тем самым проявляется и состязательность дискурса, которую отмечала Е. Булатова. «До сих пор мы смотрели, как другие страны активно преследуют свои собственные интересы. Теперь мы приступает к активным действиям», - «Российская газета» цитирует главного юридического советника госсекретаря США Джона Беллинджера. ${ }^{6}$ Реагируя на западные высказывания, журналисты развивают тему, например, одну из публикаций посвящают истории «фрлаговой традиции», вспоминая и установку флага США на Луне, и советское знамя над Рейхстагом, и Пулитцеровскую премию за снимок американских солдат, поднимающих фрлаг над японским островом Иво-Джима и т.д. ${ }^{7}$

Таким образом, до российской экспедиции «Арктика-2007» в августе 2007 г. «Российская газета» работает с арктической проблематикой лишь в контексте развития России, сохраняя при этом одинаковую динамику публикаций. В 2007 г. проявляется явная реакционность: в связи с нападками иностранных политиков количественные показатели арктических текстов в «Российской газете» возрастают, а в содержательном плане геополитический и национальный аспекты в текстах звучат громче, чем прежде. С установкой российского фрлага в Арктике в 2007 г. арктический медиадискурс переходит на качественно новый этап.

${ }^{6}$ Битва за Арктику // Российская газета. 2007. 2 авг

${ }^{7}$ Метка с последствиями // Российская газета. 2007. 10 авг.

\section{Информационная политика «Российской газеты» относительно темы освоения Арктики в 2008-2018 гг.}

На этом этапе одним из ключевых арктических событий является подписание осенью 2010 г. российско-норвежского договора о разделе спорного участка Баренцева моря. За подписанием договора последовала серия аналитических материалов об освоении Арктики в отечественной прессе, т.е. на втором этапе российского арктического дискурса преобладают не информационные материалы, как в начале столетия: с углублением проблематики происходит изменение дискурса в пользу аналитических жанров.

Подписание договора получило неоднозначную общественную оценку. «Российская газета» поддерживает официальную позицию власти и статьей Тамары Шкель от 28 марта 2011 г. издание отвечает противникам договора: «Потерять можно только то, чем владеешь. Мы никогда не владели теми районами, которые называем спорными. <..> страхуем наши будущие возможности по освоению Арктики совместно (я надеюсь) с Норвегией в режиме добрососедства и сотрудничества, а не конфронтации». ${ }^{8}$

Это подтверждает позицию норвежского исследователя Э.В. Ров о том, что Россия использует арктический регион для смягчения отношений с иностранными партнерами по другим вопросам, в которых Россия поддерживается отличной от Запада позиции, в частности, в грузин-

${ }^{8}$ Разделили море // Российская газета. 2011. 28 марта. 
ско-российских отношениях и в отношении системы ПРО.

В 2013 г. в издании вновь повышается интерес к арктической проблеме - в связи с частым обращением к принятой в 2013 г. Стратегии развития Арктической зоны России до 2020 г. Акцент газета ставит на малочисленные народы Севера, Сибири, Дальнего Востока - газета освещает их съезды, посвящает этой теме интервью. Новая для издания арктическая тема вызвана принятием Стратегии развития, которая эти вопросы охватывает, а не имевшимися и прежде проблемами северных народов. Тем самым, можно утверждать, что «Российская газета» поднимает арктическую проблематику только в связи с конкретным информационным поводом и освещает арктическую тему в сугубо узком официальном ключе.

Таким образом, в государственном медиадискурсе России проявляется явочный характер публикаций об Арктике. Появление на страницах изданиях арктического вопроса связано с конкретными информационными поводами, такими, как, напри- мер, российско-норвежский договор, Стратегия по развитию Арктической зоны России или подача новой заявки на расширение границ Арктического шельфа в 2015 г.

Во втором десятилетии XXI в. состязательность арктического дискурса находит отражение в ключе военного развития России в Арктике для защиты национальных интересов. Тема охватывает все военные проекты России в Арктике, строительство новых кораблей и техники, открытие военных частей, проведение учений и пр. В 2014 г., например, в «Российской газете» было сделано сразу 19 публикаций на эту тему, или 22 \% всех текстов об Арктике. Для сравнения: о любых иных арктических проектах в издании было опубликовано всего 24 текста, или 28 \% всех опубликованных в этот год материалов. Газета делает большой акцент на военном потенциале региона, а значит арктический дискурс приобретает такую черту как милитарность.

В целом тематическое соотношение текстов об Арктике в издании образца 2014 г. представлено графрически на рисунке 4.

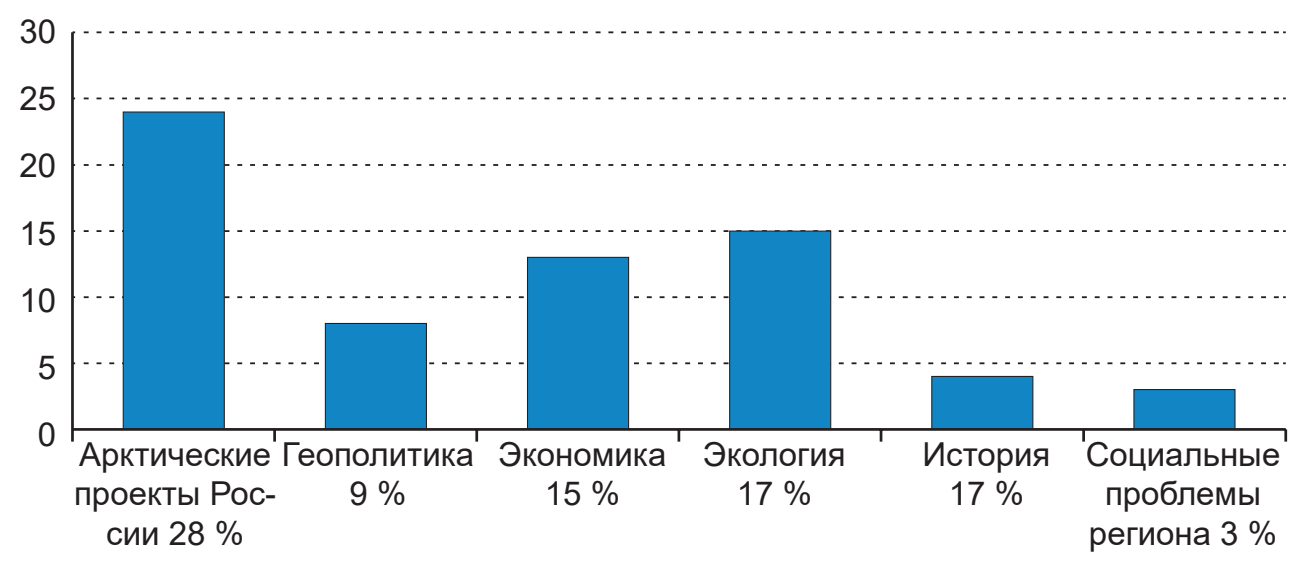

Рис. 4. Тематическое соотношение публикаций об Арктике в Российской газете в 2014 г. 
Сравнение контента арктических публикаций «Российской газеты» образца 2001 г. и 2014 г. демонстрирует тематическое расширение и увеличение количества публикаций в три раза (с 25 в 2001 г. до 86 в 2014 г.). Если в начале столетия 40 \% материалов об Арктике в «Российской газете» были посвящены истории региона, то в 2014 г. эта тема занимает лишь 5 \% от общего числа публикаций. Это позволяет говорить о том, что арктический дискурс стал столь информационно насыщен, что у журналистов появилось гораздо больше перспектив обращаться к современным информационным поводам, нежели к истории. Резкий рост демонстрирует и тема экологии и климатических изменений Арктики: от 8 \% в 2001 г. до 17 \% в 2014 г. Это вызвано, прежде всего, значительной ролью Арктики в регуляции всего климата Земного шара, активное таяние льдов в Арктике порождает новые темы для анализа последствий потепления и, следовательно, для журналистских публикаций. Ведущими в информационной политике «Российской газеты» относительно проблемы освоения Арктики, тем не менее, как и в начале столетия, остаются такие темы, как освещение арктических проектов России и экономическое развитие региона.

\section{Обсуждение и заключение}

Национальное развитие России в Арктике - ведущая тема в информационной политике «Российской газеты» относительно проблемы освоения Арктики. Это подтверждается как тематическим соотношением текстов в 2001-2018 гг., так и заголовочным комплексом публикаций. Заголовки текстов, посвященных Арктике, ярко отражают национальные амбиции в освоении региона («По курсу полюс», «Наш человек на Шпицбергене», «Москва не ослабит позиций на Шпицбергене»).

Велик и интерес издания к геополитической обстановке в Арктике, что также порождает соответствующие заголовки: «Ледниковый период», «Кому достанется Севморпуть», «Арктический передел», «Арктическая нефть уходит за рубеж» и т.п. При этом издание обычно ограничивается краткой характеристикой деятельности иностранных государств и затем возвращается к арктической политике России, подчеркивая необходимость ее усиления. ${ }^{9}$

Гораздо реже на страницах данного СМИ звучат проблемы экологии, социальной обстановки в регионе и жизни северных народов. Тематически издание сосредоточено на национальном арктическом курсе и нацелено донести читателям государственные интересы и перспективы в Артике.

${ }^{9}$ Севморпуть приглянулся соседям // Российская газета. 2006. 28 июня.

\section{СПИСОК ИСПОЛЬЗОВАННОЙ ЛИТЕРАТУРЫ}

1. Арктика: интересы России и международные условия их реализации / под ред. И.М. Могилевкина, Ю.Г. Барсегова. - Москва : Наука, 2002. - 356 с.

2. Borgese E.M. The Oceanic Circle: Governing the Seas as a Global Resource / E.M. Borgese. - Ney York : United Nations Univ. Press, 1998. - 240 p.

3. Барциц И.Н. Российский арктический сектор: правовой статус / И.Н. Барциц // Право и политика. — 2000. — № 12. - С. 106-114. 
4. Зиланов В.К. Арктическое разграничение России и Норвегии: новые вызовы и сотрудничество / В.К. Зиланов // Арктика и Север. — 2017. — № 29. - С. 28-56.

5. Dodds K. Territorial Nationalism and Arctic Geopolitics: Iceland as an Arctic Coastal State / K. Dodds, V. Ingimundarson // The Polar Journal. - 2012. - Vol. 2, no. 1. - P. 21-37.

6. Flake L.E. Contextualizing and Disarming Russia's Arctic Security Posture Center for Strategic Intelligence Research (CSIR) / L.E. Flake // The Journal of Slavic Military Studies. 2017. - Vol. 30, iss. 1. - P. 17-29.

7. Ingimundarson V. The Globalization of the Arctic and «Ideologies of the Return»/ V. Ingimundarson // Dialogue of Cultures and Partnership of Civilizations : the 14th International Likhachov Scientific Conference, Saint-Petersburg, 15-20 May, 2014. - Saint Petersburg, 2014. - P. 33-37.

8. Keskitalo E.C.H. Negotiating the Arctic: The Construction of an International Region / E.C.H. Keskitalo. - New York ; London : Routledge, 2004. - 282 p.

9. Misje A.S. Russian Hegemony in the Arctic Space? Contesting the Popular Geopolitical Discourses / A.S. Misje. — Fullerton : California State Univ. : ProQuest Dissertations Publishing, 2012. $-71 \mathrm{p}$.

10. Богдан Е.Н. Медиаобраз России как средство консолидации общества: структурно-фрункциональные характеристики : дис. ... канд. фрилол. наук : 10.01.10 / Е.Н. Богдан. - Москва, 2007. - 224 с.

11. Pincus R. Have You Been to "The Arctic"? Frame Theory and the Role of Media Coverage in Shaping Arctic Discourse / R. Pincus, S.H. Ali // Polar Geography. - 2016. Vol. 39, iss. 2. - P. 83-97.

12. Гудев П.А. Конвенция ООН по морскому праву: проблемы трансформации режима / П.А. Гудев. - Москва : НИИМЭМО РАН, 2014. - 201 с.

13. Булатова Е.И. Средства вербальной агрессии как инструмент информационных войн (на примере Арктического медиадискурса) / Е.И. Булатова // Филологические науки. Вопросы теории и практики. 2016. — № 8, ч. 1 (62). - С. 88-91.

14. Виноградов С.И. Язык газеты в аспекте культуры речи / С.И. Виноградов // Культура русской речи и эффрективность общения / под ред. Л.К. Граудиной, Е.Н. Ширяева. - Москва : Наука, 1996. - Гл. 10. - С. 281-317.

15. Чевозерова Г.В. Информационная политика СМИ / Г.В. Чевозерова // Вестник ВГУ. Серия: Филология. Журналистика. — 2011. - № 1. - С. 206-213.

16. Конышев В.Н., Сергунин А.А. Арктика в международной политике: сотрудничество или соперничество? / В.Н. Конышев, А.А. Сергунин ; под ред. И.В. Прокофьева. Москва : Изд-во РИСИ, 2011. - 194 с.

17. Арктика в системе международного сотрудничества и соперничества / П.С. Журавлёв, О.В. Зарецкая, А.О. Подоплекин [и др.]. - Архангельск : СОЛТИ, 2015. - 167 с.

18. Rowe E. A Dangerous Space? Unpacking State and Media Discourses on the Arctic / E. Rowe // Polar Geography. - 2012. - Vol. 36, iss. 3. - P. 1-12.

19. Лукин Ю.Ф. Великий передел Арктики / Ю.Ф. Лукин. - Архангельск : Изд-во Северного (Арктического) федер. ун-та, 2010. - 399 с.

20. Гнединская А. Флаг России окажется на дне Северного Ледовитого океана / А. Гнединская // Московский комсомолец. - 2007. - 23 июля.

\section{REFERENCES}

1. Mogilevkin I.M., Barsegov Yu.G. (eds). Arktika: interesy Rossii i mezhdunarodnye usloviya ikh realizatsii [Arctic: Russia's Interests and International Conditions for their Implementation]. Moscow, Nauka Publ., 2002. 256 p.

2. Borgese E.M. The Oceanic Circle: Governing the Seas as a Global Resource. Ney York, United Nations University Press, 1998. 240 p.

3. Bartsits I.N. Russian Arctic Sector: Legal Status. Pravo $i$ politika = Law and Politics, 2000, no. 12, pp. 106-114. (In Russian).

4. Zilanov V.K. Delimitation Between Russia and Norway in the Arctic: New Challenges and Cooperation. Arktika i Sever = Arctic and North, 2017, no. 29, pp. 28-56. (In Russian).

5. Dodds K., Ingimundarson V. Territorial Nationalism and Arctic Geopolitics: Iceland as an Arctic Coastal State // The Polar Journal, 2012, vol. 2, no. 1, pp. 21-37. 
6. Flake L.E. Contextualizing and Disarming Russia's Arctic Security Posture Center for Strategic Intelligence Research (CSIR). The Journal of Slavic Military Studies, 2017, vol. 30, iss. 1 , pp. 17-29.

7. Ingimundarson V. The Globalization of the Arctic and "Ideologies of the Return." Dialogue of Cultures and Partnership of Civilizations. The $14^{\text {th }}$ International Likhachov Scientific Conference, Saint-Petersburg, May 15-20, 2014. Saint Petersburg, 2014, pp. 33-37.

8. Keskitalo E.C.H. Negotiating the Arctic: The Construction of an International Region. New York, London, Routledge, 2004. 282 p.

9. Misje A.S. Russian Hegemony in the Arctic Space? Contesting the Popular Geopolitical Discourses. Fullerton, California State University, ProQuest Dissertations Publishing, 2012. $71 \mathrm{p}$.

10. Bogdan E.N. Mediaobraz Rossii kak sredstvo konsolidatsii obshchestva: strukturnofunktsional'nye kharakteristiki. Kand. Diss. [Media Image of Russia as a Means of Consolidation of Society: Structural and Functional Characteristics. Cand. Diss.]. Moscow, 2007. 224 p.

11. Pincus R., Ali S.H. Have You Been to "The Arctic"? Frame Theory and the Role of Media Coverage in Shaping Arctic Discourse. Polar Geography, 2016, vol. 39, iss. 2, pp. 83-97.

12. Gudev P.A. United Nations Convention on the Law of the Sea: Regime Transformation Problems. Moscow, Primakov National Research Institute of World Economy and International Relations, Russian Academy of Sciences Publ., 2014. 201 p.

13. Bulatova E.I. Means of Verbal Agression as a Tool of Information Wars (by the Example of the Arctic Media Discourse). Filologicheskie nauki. Voprosy teorii i praktiki= Philological Sciences. Issues of Theory and Practice, 2016, no. 8, pt. 1 (62), pp. 88-91. (In Russian).

14. Vinogradov S.I. The Language of the Newspaper in the Aspect of Speech Culture. In Graudina L.K., Shiryaev E.N. (eds). Kul'tura russkoi rechi i effektivnost' obshcheniya [Culture of Russian Speech and Effectiveness of Communication]. Moscow, Nauka Publ., 1996, ch. 10, pp. 281-317. (In Russian).

15. Chevozerova G.V. Media Information Policy. Vestnik Voronezhskogo gosudarstvennogo universiteta. Seriya: Filologiya. Zhurnalistika $=$ Proceedings of Voronezh State University. Series: Philology. Journalism, 2011, no. 1, pp. 206-213. (In Russian).

16. Konyshev V.N., Sergunin A.A.; Prokofiev I.V. (ed.). Arktika v mezhdunarodnoi politike: sotrudnichestvo ili sopernichestvo? [Arctic in International Politics: Cooperation or Rivalry?]. Moscow, Russian Institute for Strategic Studies Publ., 2011. 194 p.

17. Zhuravlev P.S., Zaretskaya O.V., Podoplekin A.O., Repnevsky A.V., Tamitsky A.M. Arktika $v$ sisteme mezhdunarodnogo sotrudnichestva i sopernichestva [The Arctic in the System of International Cooperation and Competition]. Arkhangelsk, SOLTI Publ., 2015. 167 p.

18. Rowe E. A Dangerous Space? Unpacking State and Media Discourses on the Arctic. Polar Geography, 2012, vol. 36, iss. 3, pp. 1-12.

19. Lukin Y.F. Velikii peredel Arktiki [The Great Redistribution of the Arctic]. Arkhangelsk, Northern (Arctic) Federal University Publ., 2010. 399 p.

20. Gnedinskaya A. The Flag of Russia Will Be Planted on the Bottom of the Arctic Ocean. Moskovskii komsomolets, 2007, July 23.

\section{ДЛЯ ЦИТИРОВАНИЯ}

Авдонина Н.С. Проблема освоения Арктики в государственном медиадискурсе России: на примере «Российской газеты», официального издания Правительства РФ / H.C. Авдонина, C.О. Долгобородова.—DOI: 10.17150/2308-6203.2019.8(4).735-746 // Boпросы теории и практики журналистики. - 2019. - Т. 8, № 4. - С. 735-746.

\section{FOR CITATION}

Avdonina N.S., Dolgoborodova S.O. Coverage of the Arctic Development in Russian Mass Media Discourse (by the example of "Rossiyskaya Gazeta"). Voprosy teorii i praktiki zhurnalistiki = Theoretical and Practical Issues of Journalism, 2019, vol. 8, no. 4, pp. 735-746. DOI: 10.17150/2308-6203.2019.8(4).735-746. (In Russian). 